\title{
The Demand for Primary Health Care Services in the Bicol Region of the Philippines*
}

John S. Akin

University of North Carolina at Chapel Hill and World Bank

Charles C. Griffin

Yale University

David K. Guilkey and Barry M. Popkin

University of North Carolina at Chapel Hill

\section{Introduction}

The strategies selected to provide health services to rural areas in lowincome countries are motivated in part by the following commonly held assumptions about existing health conditions and medical service demand patterns in such countries: (1) many Third World health problems are thought to be susceptible to elementary types of care and simple drugs that can be supplied by paraprofessionals; (2) conventional modern medical resources are thought to be located primarily in urban areas and therefore to be inaccessible to rural households; and (3) the economic aspects of the demand for medical care-income, time costs, and cash costs - are thought to be extremely important deterrents to using medical services. The idea that simple interventions, usually of a preventive type, will solve many rural health problems is probably incontrovertible. However, although the proper interventions can be dictated by a public health or epidemiological analysis, the planned effects of such interventions may be offset by unexpected behavioral patterns of both target and nontarget groups.

The presumption that modern medical personnel serve a relatively wealthy urban clientele leads planners to think that, in supplying new services to rural areas, they are filling modern medical service vacuums. Little emphasis is therefore given to the niche filled by these new services among already existing modern and traditional sources of care in rural areas. There is a lack of understanding, consequently, of 
why people might desire to use these new services or, similarly, why they may stay away.

The assumption that primary health care (PHC) services must be provided for free or for only a nominal charge has two important effects. First, it requires that PHC programs be financed either by international agencies or by having low-income countries reallocate scarce national revenues to rural health services. Second, it means that the level of care provided by community health services becomes limited by outside constraints unrelated to potential demand for the services or to the level of care that local residents are willing to finance.

In this paper we analyze the demand for primary health careoutpatient, prenatal, obstetrical, well-baby, and immunization services-using community and household data from one of the poorest regions of the Philippines. Our interest is to understand demand patterns better and to analyze how this new information might modify the strategies chosen to implement PHC goals. The presentation is organized as follows: in the next section we discuss the theoretical issues that guide our choice of demand model; in the third section we describe the region and the data; in the fourth section we present our empirical work; and in the fifth section we draw conclusions about the issues raised in this introduction.

\section{Demand for Medical Services}

Behavior in medical markets is distinguished by the roles that physical need and life-cycle patterns play in determining demand. Circumstances, such as accidents, pregnancies, and infections, often dominate health care consumption decisions. Many needs are age and sex specific, such as immunizations early in life, the risk of pregnancy during fertile years for women, and the onset of degenerative diseases late in life. Institutionally, medical markets are distinguished by intentional interference with the price system, both by governments, which subsidize medical service consumption through welfare programs, and by health insurance, which spreads risk and reduces direct cash costs to consumers.

The major policy issues for demand analysis in high-income countries are the high cost of medical care and the possible overuse of physician services, ${ }^{1}$ whereas in low-income countries the problems are access to facilities, capturing true demand patterns (esp. the use of traditional practitioners and self-care), and demand creation, or how to assure that new government services are used. Although anthropologists and geographers have been active in collecting and analyzing medical service utilization data in low-income countries, only Heller has approached the issue from an economic perspective. ${ }^{2}$ Heller found very little sensitivity to prices for total annual medical visits made by a rural Malaysian sample, although he did find that the relative prices of private and governmental clinics affected the decision of which to use. 
Our theoretical model is virtually identical to one proposed by Acton and modified by Heller. Consumers maximize a utility index over a vector of purchased medical services and a composite of all other goods. Each medical service commands a cash price and a time price. We derive a system of demand equations in which the choice of medical service is a function of exogenous time and cash prices, income, and controls for other related variables. Only individuals who have a demonstrated need for medical services, by virtue of being sick, pregnant, or newly born, are considered to be actively participating in medical markets appropriate to their needs. ${ }^{3}$

The model is summarized below (eq. [1]) in reduced form, as a system of demand equations:

$$
Q_{i j}=f_{i j}\left(\boldsymbol{p}_{p u}, \boldsymbol{p}_{p r_{j}}, \boldsymbol{p}_{t r_{j}}, \boldsymbol{t}_{p u_{j}}, \boldsymbol{t}_{p r_{j}}, \boldsymbol{t}_{t r_{j}}, Y_{j}, Z_{j}\right)
$$

where

$Q_{i j}=$ whether medical service $i$ is used by the $j$ th individual, where

$i=$ public modern, private modern, traditional, or no care, and

$j=$ all sick people, pregnant women, or newborns, the sample depending on the model.

$\boldsymbol{p}=$ vector of facility-level cash prices associated with each service (including visit price, drug cost, and transport cost):

$p u_{j}=$ closest public clinic or hospital serving the $j$ th individual's village;

$p r_{j}=$ closest private clinic or hospital serving the $j$ th individual's village; and

$t r_{j}=$ closest traditional healer or midwife serving the $j$ th individual's village.

$\boldsymbol{t}=$ vector of facility-level time costs associated with each service (waiting time, transportation time).

$Y_{j}=$ household income for the $j$ th individual.

$\mathbf{Z}_{j}=$ a vector of social, demographic, and biological control variables for the $j$ th individual.

Our empirical work differs from that of other researchers in that we attempt to explain the choice of practitioner (or whether to use a service, such as immunizations, at all) rather than total medical visits. Except for Heller, previous empirical work has concentrated on explaining total annual inpatient and outpatient visits. Our disaggregation of medical consumption into different services results from the fact that medical care is not a homogenous good. Outpatient and prenatal care, for example, are recognized to be aimed at different consumers.

This analysis combines facility-level price data with individuallevel observations. Other researchers have relied primarily on house- 
hold-level expenditure data and have therefore been forced to substitute average expenditures by users for otherwise missing expenditures of nonusers. In addition, because expenditures (price times quantity) depend on demand behavior, such a procedure is equivalent to explaining the quantity purchased in part by that same variable multiplied by a scalar. Because our price data are collected from facilities, we eliminate these two problems.

\section{The Region and the Data}

\section{Description of the Bicol Region}

The Philippine nation is composed of 7,100 islands lying just above the equator in Southeast Asia. It is a middle-income developing country containing about 60 million people in 1980 and having an average per capita GNP of $\$ 600$ in 1979 . There are 12 regions, which are divided into provinces and independent chartered cities, both of which are subdivided into municipalities. Municipalities are composed of barangays (villages or city districts), which are the focus of our communitylevel analysis.

The organization of the Ministry of Health parallels these political divisions. The Philippine General Hospital in Manila is at the apex, large provincial hospitals are located in provincial capitals, and smaller 25-bed emergency hospitals serve outlying municipalities. Most municipalities contain at least one rural health unit (RHU) that provides free outpatient, delivery, and well-baby services. Increasingly, trained midwives connected to RHUs work as barangay health aides stationed in their barangays. This system is financed by contributions from each level of government, with assistance from international agencies, primarily for the barangay health aide program.

About $40 \%$ of government hospital beds are located in Manila (which has $13 \%$ of the population), but about $90 \%$ of the clinics are located outside Manila. ${ }^{4}$ In addition to the governmental health system, there is an equally large private medical sector distributed in an almost identical manner among provinces. These numbers may suggest that the Philippines is atypically well covered by medical personnel, but, on a national level, the situation is actually similar to that in other Asian and South American countries. ${ }^{5}$

The Bicol region, the area to which our analysis is confined, lies about 300 kilometers southeast of Manila. It consists of four provinces on Luzon Island (Albay, Camarines Norte, Camarines Sur, and Sorsogon) and two separate island provinces (Catanduanes and Masbate). The terrain is mountainous, with many isolated and inaccessible areas. It contains about 3.5 million (1980 census) people, $83 \%$ of whom live in rural areas. The region's share of the nation's GDP was $3.3 \%$ in 1979 , although the region accounted for $7.6 \%$ of the total Philippine population. 
Description of the 1978 Bicol Multipurpose Survey (BMS78)

The Bicol Multipurpose Survey contains data collected in 1978 on a sample of 1,903 households and their 12,000 residents in 100 barangays located in Albay, Camarines Sur, and Sorsogon. ${ }^{6}$ These three survey provinces are the location of a large rural development project. They contain $62 \%$ of the Bicol region's total land mass and $69 \%$ of the regional population. The 100 survey barangays were chosen randomly to be representative of the area in terms of both urban-rural location and household socioeconomic status. They are located in 47 municipalities (out of a total of 71 municipalities in the three provinces) and had a population of 338,009 in 1977 .

We encountered two problems in trying to use the BMS78 data to estimate our demand equations. ${ }^{7}$ First, it supplies incomplete information on the full range of traditional and modern health services available to survey households. Second, although the survey provides adequate data on sickness episodes, pregnancies, and births, the prices of the relevant medical services are not available.

\section{Description of the Bicol Multipurpose Supplemental}

Survey, 1981 (BMSS81)

To solve these problems, we undertook a survey in 1981 of virtually every medical practitioner or facility that served the 100 barangays surveyed in 1978. Field investigators inventoried 518 facilities by visiting the barangays and asking key informants to identify the government; private, modern; and traditional facilities or individual practitioners commonly used by residents. Subsequent visits were made to the facilities to gather data on payment practices, hours of operation, available medical personnel, and transport costs to the barangays served. In addition, detailed price information was gathered on adult outpatient, child outpatient, clinic delivery, home delivery, prenatal, well-baby, and child immunization services.

To summarize, the data available for this study include individual information on practitioner choices for sickness episodes occurring during the month prior to the 1978 Bicol survey and on prenatal, delivery, and postnatal care for pregnancies occurring during the year prior to the survey. We match community information on medical service prices and availability with these individual observations to explain practitioner choices.

Matching 1981 health facility data with 1978 household data requires the assumption that the same services were available in 1978 as in 1981 and that the relative prices of these services remained constant. Apart from the fact that we have no alternative but to do this, these are reasonable assumptions for several reasons. First, the only major change in government services over the period was a barangay health worker program that had been operating for less than a year and had 
fielded less than $17 \%$ of the intended personnel by November 1981, the time of our survey. Second, exactly the same number of physicians (373) was accredited by the Philippine Medical Care Commission for Albay, Camarines Sur, and Sorsogon in 1981 as in 1978. This number tends to fluctuate slightly from year to year, and it probably underestimates the total number of physicians; however, it is the only available statistic that measures physician supply. Third, we found such an unexpectedly extensive network of private and public facilities, as well as an almost saturation-level of traditional practitioners, that changes at the margin in any of these three sectors would be unlikely to seriously disrupt either the extent of coverage or relative prices.

\section{Empirical Findings}

Table 1 lists the demand models that we estimate, along with their distinguishing characteristics. The last column of this table lists the method of estimation used for each dependent variable. The tobit method is used for prenatal care because we have a mass of observations at the zero point, with other observations spread over a continuous range. The use of tobit logically assumes an underlying continuous variable that contains an error term that follows a normal distribution. This is, of course, a very common assumption in statistical analysis.

Probit is used to estimate the well-baby and immunization equations, where the dependent varible is dichotomous. The probit technique is also based on an assumed normal distribution for the errors. In the remaining three cases, the dependent variable is an unordered polytomous response. We would prefer to use the conditional probit model for these cases so that our error term assumption would be consistent across all models. However, because of the well-known computational difficulty of the probit method when there are more than three categories for the dependent variable, the logit model is used. The more computationally efficient logit technique has been shown to give estimated parameters that are quite similar to probit estimates. ${ }^{8}$

The independent variables used in our analysis are defined in table A1. Table A2 contains descriptive statistics on the independent variables used in the adult and child outpatient models, and table A3 contains similar statistics for the independent variables of the prenatal, delivery, well-baby, and immunization models. We must point out two minor problems that might be missed except by careful examination of these Appendix tables. First, because of problems with the BMS78 data tapes available at the time of this research, we do not have a reliable household income variable. We compensate by substituting an asset variable, as explained in table A1, to approximate relative permanent income levels. Second, the absence of market work and wage data (this is a function of the first problem) prevents proper weighting of time costs by individuals' shadow value of time. Using unweighted 


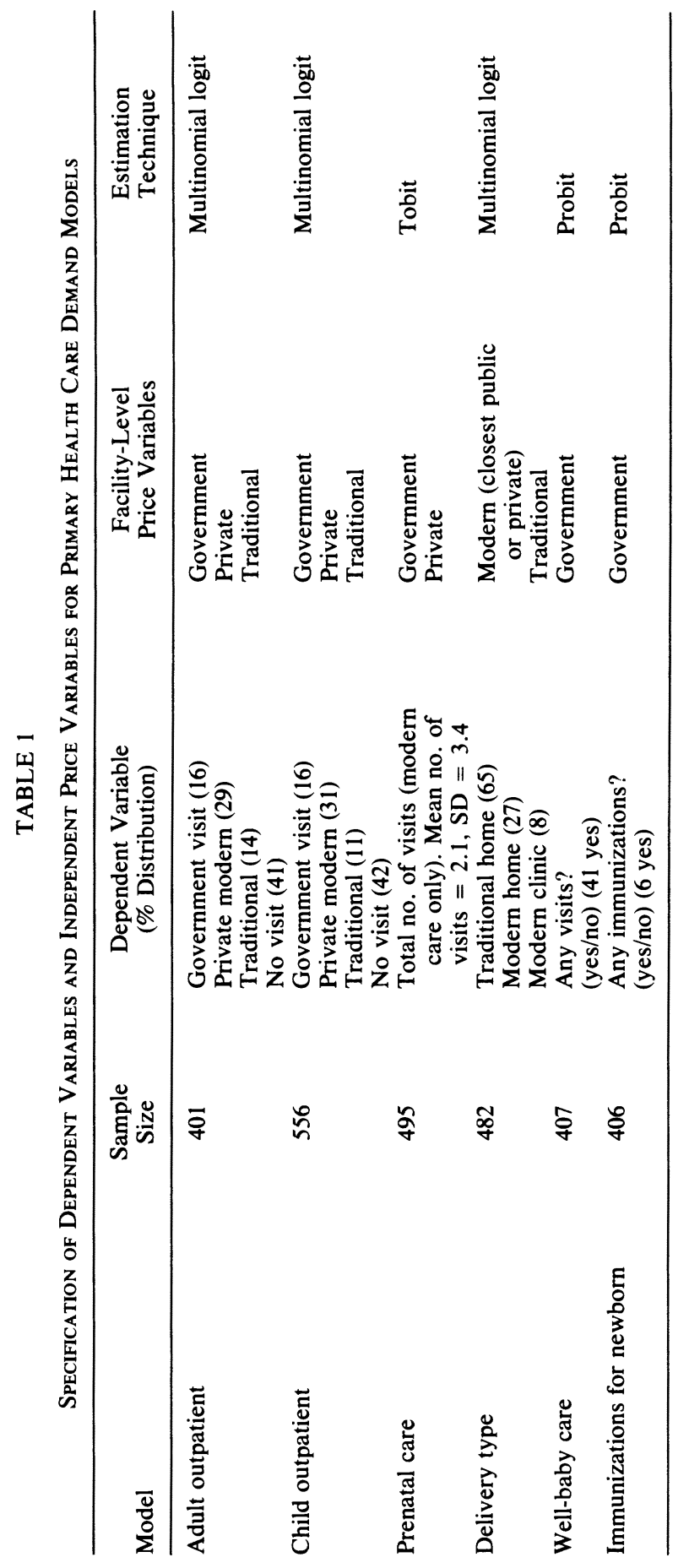


time cost variables is tantamount to assuming constant opportunity cost of time across households, which is unsatisfactory. We partially overcome this problem in all but the adult outpatient model by using a qualitative variable to measure whether a mother works away from home and another variable to measure the number of children, as a way to capture indirectly mothers' opportunity costs.

The actual estimation results for the tobit, logit, and probit equations are presented in tables A4-A9. Because of the complexity of interpretation of direct tobit, logit, and probit coefficients, plus a desire that the results across equations be readily comparable, we do not discuss these tables. Instead we base our discussion of the empirical results on summary tables 2 and 3, which are much simpler to describe. In these tables, we present estimates of the changes in the estimated probability of using each service or practitioner that results when one independent variable is changed while all other independent variables are held constant at their sample averages. We change each continuous variable by $10 \%$ and compare each of the new estimated probabilities with the probabilities estimated when all variables are at their sample means. For the dummy independent variables, we present probability changes based on movements of the variable from the value zero to the value one, with all other independent variables held constant at their sample average values.

\section{Adult Outpatients}

The sample statistics for adult outpatients reveal the following characteristics: about $20 \%$ of these outpatients live in urban areas, $10 \%$ are covered by some kind of health insurance, the average age is 40 , the average education is about 7 years, and the sample is evenly split between males and females. About $30 \%$ of these patients report the illness to be serious. The sample faces an average transport time of about 5 minutes to the closest traditional healer and 24 minutes to the closest public or private, modern facility that offers outpatient services. At $60 \%$ of the public clinics and $80 \%$ of the private clinics the patients can expect to be examined by a doctor. About $20 \%$ of the traditional practitioners treat none of the five common illnesses on which data were collected in the facility survey. The index of drug costs is, on the average, almost 100 times higher at public clinics than at traditional practitioners and 10 times higher at private clinics than at public clinics. Average visit prices at public clinics are almost zero, whereas they are P2 at traditional healers and P11 at private clinics.

The most important finding from the outpatient models is a lack of statistical significance for the economic variables. No matter what the severity of illness - or the age group - the cash cost of a visit, transportation time, transportation cost, waiting time, and insurance coverage have almost no power in explaining visit choices. The variables that 
measure quality also have almost no explanatory power, which is a highly counterintuitive result. Our proxy for income, the level of personal assets, is a significant predictor of choosing a private practitioner over other practitioners in several cases, but the magnitude of the effect is extremely small. Older adults are more likely to choose some practitioner over none, but age is not a good predictor of choice among different practitioners. Adult men are more likely to use private sources of care. Urban residence has no statistically significant effect on the visit choices of adults but makes it more likely that children will receive public, modern care rather than no care. Note that this urban effect must be a behavior-, personality-, or work-related effect because the time and distance variables usually proxied by urban residence are already accounted for. Education increases the probability that some kind of practitioner is chosen over none, but it does not appear consistently to affect the choice among practitioner types. It is often assumed that higher levels of education divert people from traditional care; this does not happen for our sample.

The one variable that overshadows all others in explaining practitioner choice is the perceived severity of the illness. A serious illness causes adults and children to use some practitioner rather than none, and it substantially increases the probability of choosing a private, modern practitioner. For the average adult, perceiving the sickness to be serious raises the probability of a private visit by $30 \%$ and reduces the probability of no visit by $34 \%$. It raises the probability of a public visit by only $4 \%$ and leaves the probability of a traditional visit virtually unchanged. The strongest effect of a serious illness for adults is in transferring people from the "no visit" category to the "private" category. For children, the effect is almost identical.

Closer inspection of the data and other model estimates not reported here shows that there is a surprisingly high correlation between being poor and perceiving an illness to be serious. The seriously ill sample comes from households whose average asset value is over $40 \%$ less than the asset value for the non-seriously-ill sample. There are many possible explanations for this situation: the seriously ill may be poor because they are ill and cannot work; they may be ill because they are poor; they may not report themselves sick until they are debilitated; or they may be more likely to call even minor illnesses serious. The first idea, that they are poor because they are sick, challenges the direction of causation in the model, but this possibility is probably eliminated by the fact that our asset variable is more a measure of average income over a number of years than of current income. Our measure would not capture the phenomenon of low current income caused by illness unless it were a chronic sickness that had caused the household either to sell off assets or never to accumulate them. Because the survey asked separately about disabilities and their related 


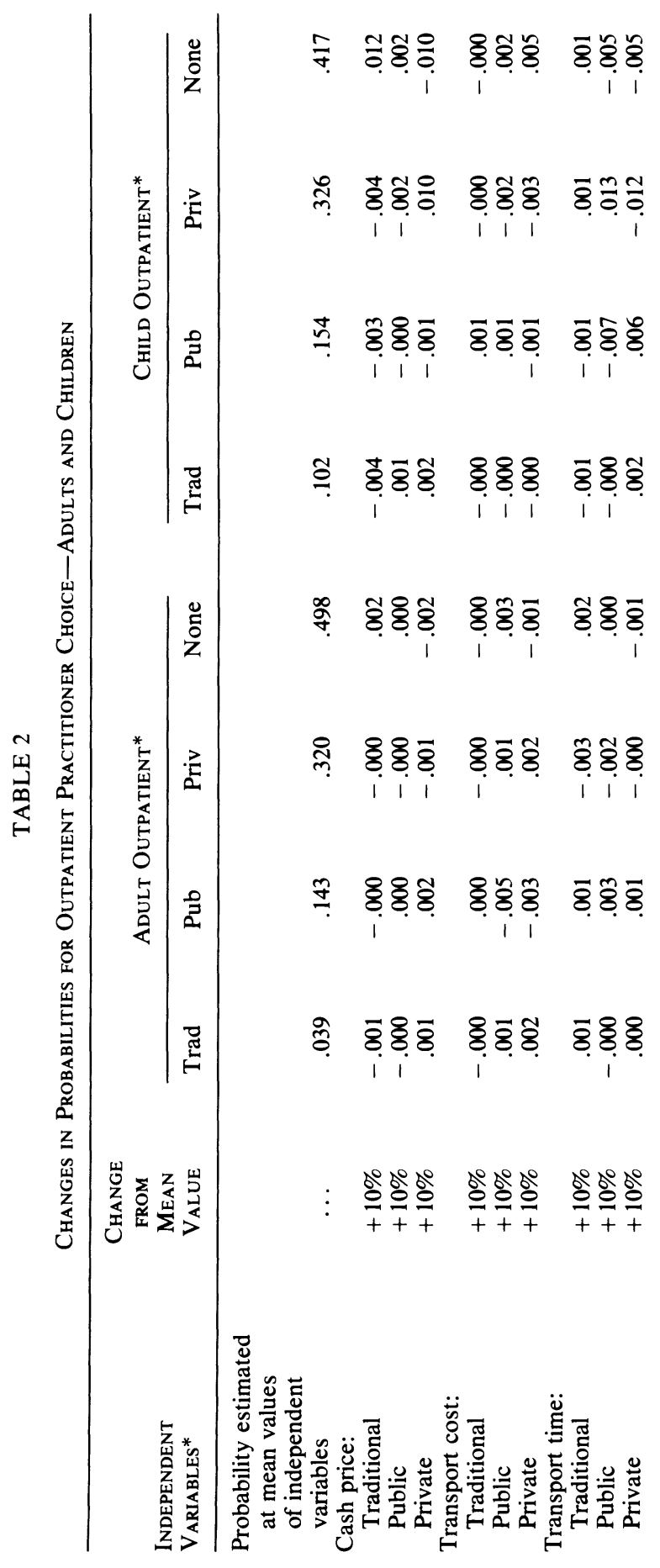




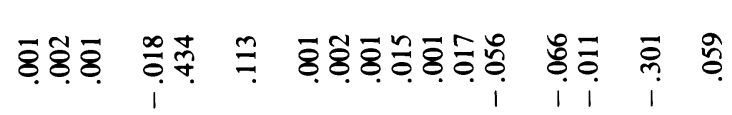

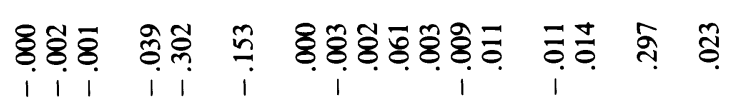

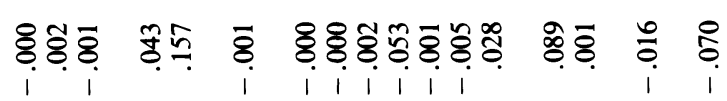

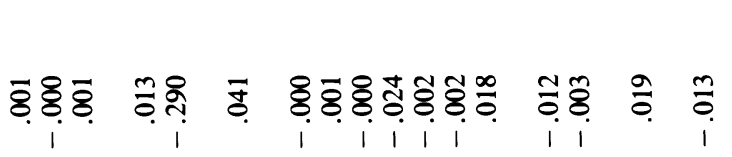

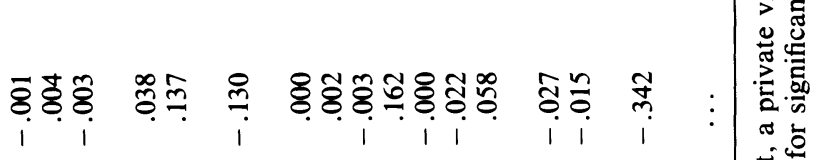

10

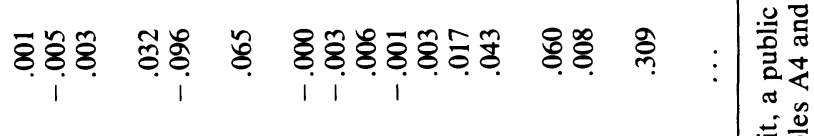

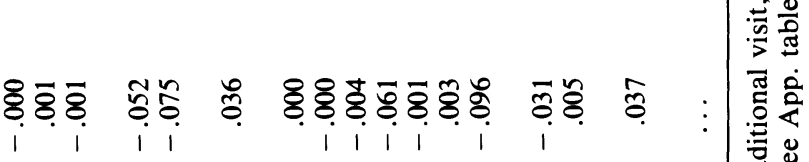

i i i

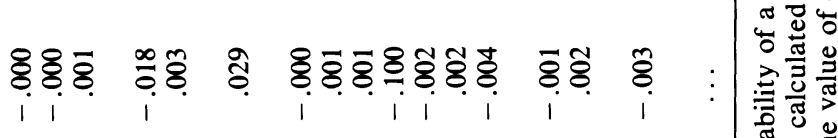

1
11

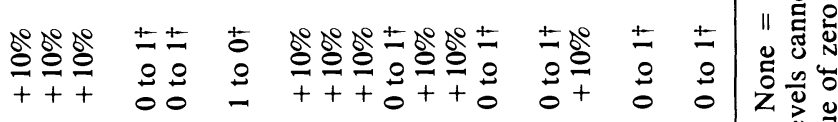

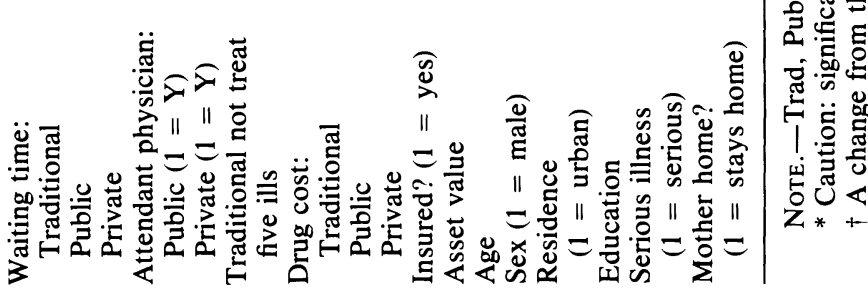




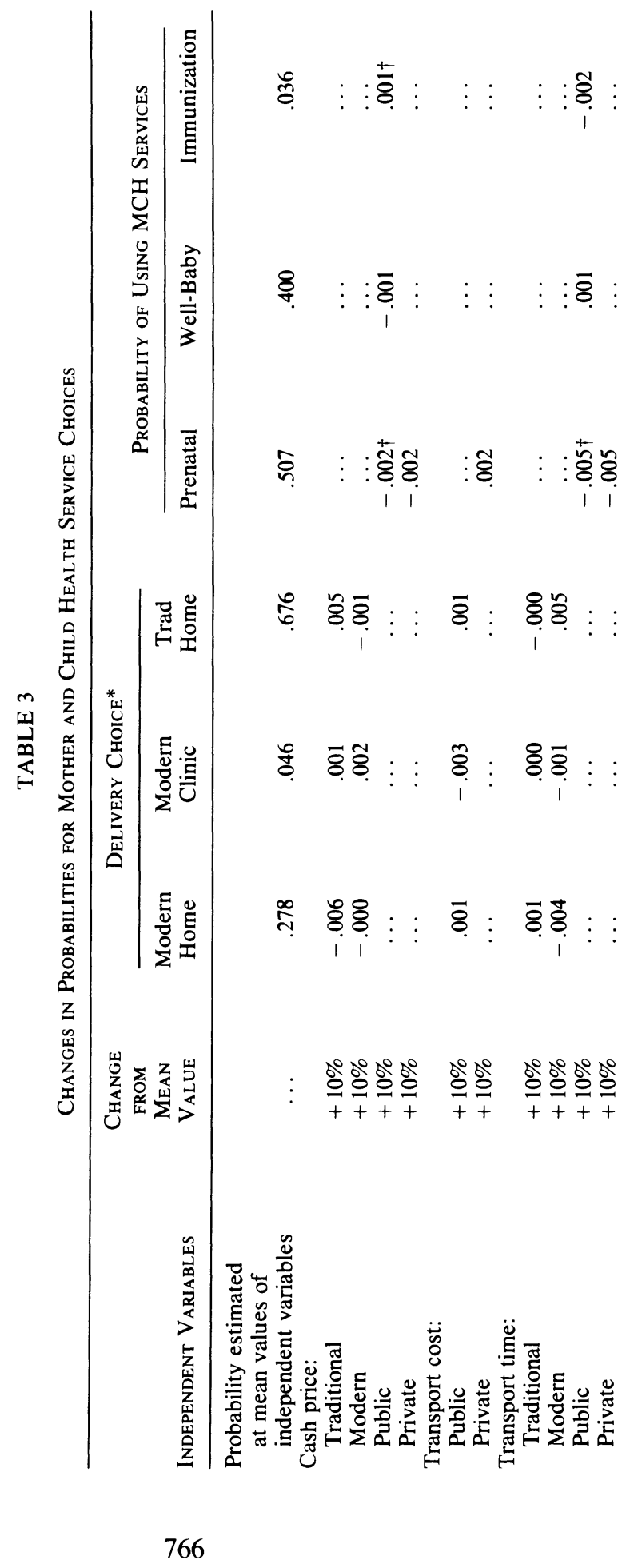




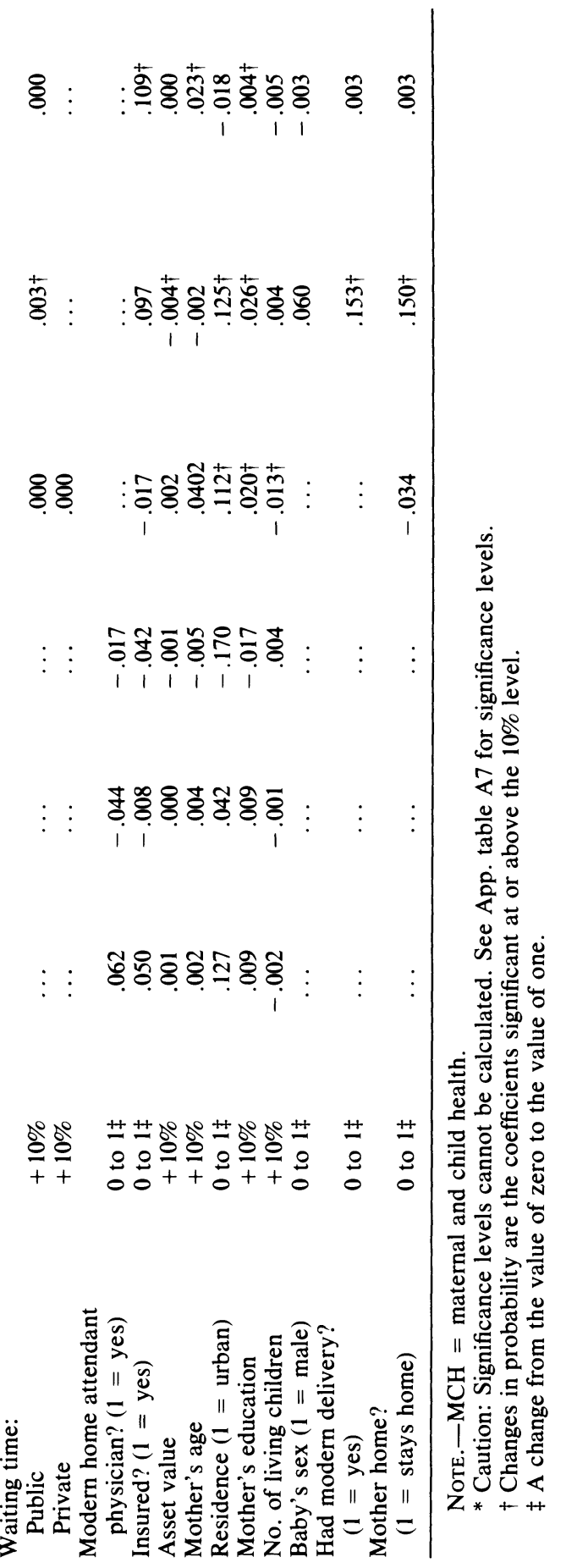


hospitalizations, the chonically ill would appear in our outpatient category only if they were sick-independent of their disabilities-during the previous month. Therefore, it would be surprising to find that being sick caused the seriously ill sample to be so poor. We are confident that the causation is from poverty to the perceived seriousness of the illness and not vice versa. We are left with the fact that the choice made by the seriously ill is predominantly to use private physicians, and the seriously ill are generally the poorest in our sample.

To summarize, we find that the pecuniary and nonpecuniary costs of using medical care are not important predictors of the choice of practitioner for either adults or children. There are isolated instances of significant variables, but these are minor exceptions to a preponderance of evidence that cost and income are not important to the joint decisions of whether and where to seek care. The overwhelmingly important explanatory variable is seriousness of the illness, which cuts across all socioeconomic lines and forces the poor and rich to act the same way: they tend to seek out private, modern care.

\section{Delivery Services}

The results for the delivery model suggest that the choice of a modern or traditional birth attendant is also made on other than economic grounds. In no case is the price of a traditionally attended birth a statistically significant predictor, even though it appears that traditional attendances are often more expensive than those by rural healthunit midwives. ${ }^{9}$

The identity of the modern attendant has an interesting effect. If the modern home attendant is a doctor, the probability of a modern home delivery is increased relative to the probability of a modern clinic delivery, but there is no effect on whether a modern home birth is chosen over a traditionally attended birth.

Transport time to a modern facility increases the probability of a traditional home birth, but this effect is so small that a $10 \%$ increase in transport time for a modern midwife increases the probability of a traditional attendance by less than $1 \%$. In addition, neither household assets nor insurance coverage affects the traditional-versus-modern decision.

The important explanatory variables in the delivery model are urban residence and mother's education. Changing residence from rural to urban while holding variables constant increases the probability of a modern home birth by $13 \%$ and decreases the probability of a traditional home birth by $17 \%$. It also increases the probability of a modern clinic birth by about $4 \%$. As in the outpatient models, because distance is already controlled for, the urban variable seems to be measuring differences in orientation, efficiency of markets, or migrant personality traits. The pattern that emerges is that urban residents are 
more likely to choose modern deliveries and that more of these deliveries will be at home than at clinics. Raising a mother's education by $10 \%$ (almost an additional year of schooling) decreases the probability of a traditional birth by $2 \%$.

\section{Prenatal Care, Well-Baby Care, and Immunization Services}

It is difficult to find consistent patterns in the factors that determine demand for prenatal care, well-baby care, and immunizations. The economic variables have stronger effects than in the other models but show no consistent pattern: for prenatal care, costs depress visits, but for well-baby care and immunizations, cash costs and waiting time have counterintuitive positive effects on use, suggesting some kind of unmeasured quality phenomenon.

The demographic variables, as in the outpatient and delivery models, are the most important. Urban residence strongly increases the probability of prenatal and well-baby visits but has no effect on immunizations. More education increases the probability of all three types of visits, and older women appear to demand more prenatal and immunization services when the number of children is controlled for. An important policy variable in these two models is whether the delivery was attended by a modern practitioner. This variable measures the continuity of care or the ability of the modern sector to follow through on postbirth services. Having a modern delivery increases the probability of a well-baby visit by about $15 \%$ but has no statistically significant effect on the probability of an immunization. The most striking feature of these models, however, is the extremely low level of immunization coverage. It is tempting to suggest that this is caused by measurement error, but other studies in the Philippines have found similar patterns.

\section{Conclusions}

Quality

One of the most important and neglected demand issues in PHC programs is the quality of services. In our analysis we control for quality in modern facilities by whether outpatients are seen by doctors, and we use a somewhat different variable to control for the quality of traditional healers. In no case are these quality variables statistically significant, indicating that quality, approximated by the identity of the practitioner most likely to be seen, does not affect our sample's medical service choices. We observe, however, a strong movement of patients toward private physicians for illnesses perceived to be serious, almost certainly a quality-related phenomenon. We also detect, in two odd price results for well-baby and immunization care, a possible facility-level quality effect. These patterns suggest that Bicolano patients do not pay attention so much to the identity of the practitioner whom 
they see (our control variable) as they do to the orientation (modern vs. traditional) and type (private vs. public) of facility. For example, in the delivery model, physicians' willingness to perform home deliveries increases the probability that a modern home delivery is chosen over a clinic delivery, but it does not affect the choice between traditional and modern home births.

Facility type and personnel are not entirely separate issues, but the distinction is pursued here because if the evidence can be generalized, it implies that the character of the care delivered through primary health care (PHC) programs may be more important to patients than the identity of the workers. The PHC programs usually pay considerable attention to the identity of health workers (e.g., community selection) but often give inadequate attention to training and field supervision. ${ }^{10}$

\section{Unavailability of Modern Medical Resources}

The belief that few modern medical resources are available in rural areas is usually supported by aggregative manpower and per capita hospital bed comparisons for low- and high-income countries. The data from our facility survey provide evidence of the range of medical service choices that face a random sample of communities in a specific poor rural area. Table 4 contains three measures of accessibility for each type of facility or practitioner operating near the Bicol region survey barangays. Except for four or five outlying barangays there appears to be ready availability of public and private health services and an abundance of traditional healers. Despite the accessibility of modern care, traditional healers continue to be used by about $14 \%$ of the outpatients, and traditional midwives are used for almost $70 \%$ of the deliveries.

Rather than assuming that modern medical personnel vacuums exist in such rural areas as our survey area, it appears that in some cases it may be more realistic to assume that government health workers will compete with other practitioners. Traditional healers will generally be the principal competitors of village-based primary care workers, and many sick people probably will not stop using traditional practitioners. In some cases it may be possible to motivate existing suppliers to deliver the care thought to be missing.

\section{Cost as a Determinant of Medical Care Use}

An effort to cut medical costs and a presumption that rural residents cannot pay for care seem to be important elements of PHC programs. In the results from our demand analysis for the Bicol region, however, visit prices appear to have little effect on whether services are used or on which practitioner is chosen. The threshold at which prices even begin to affect the medical care decision process for our sample is quite 


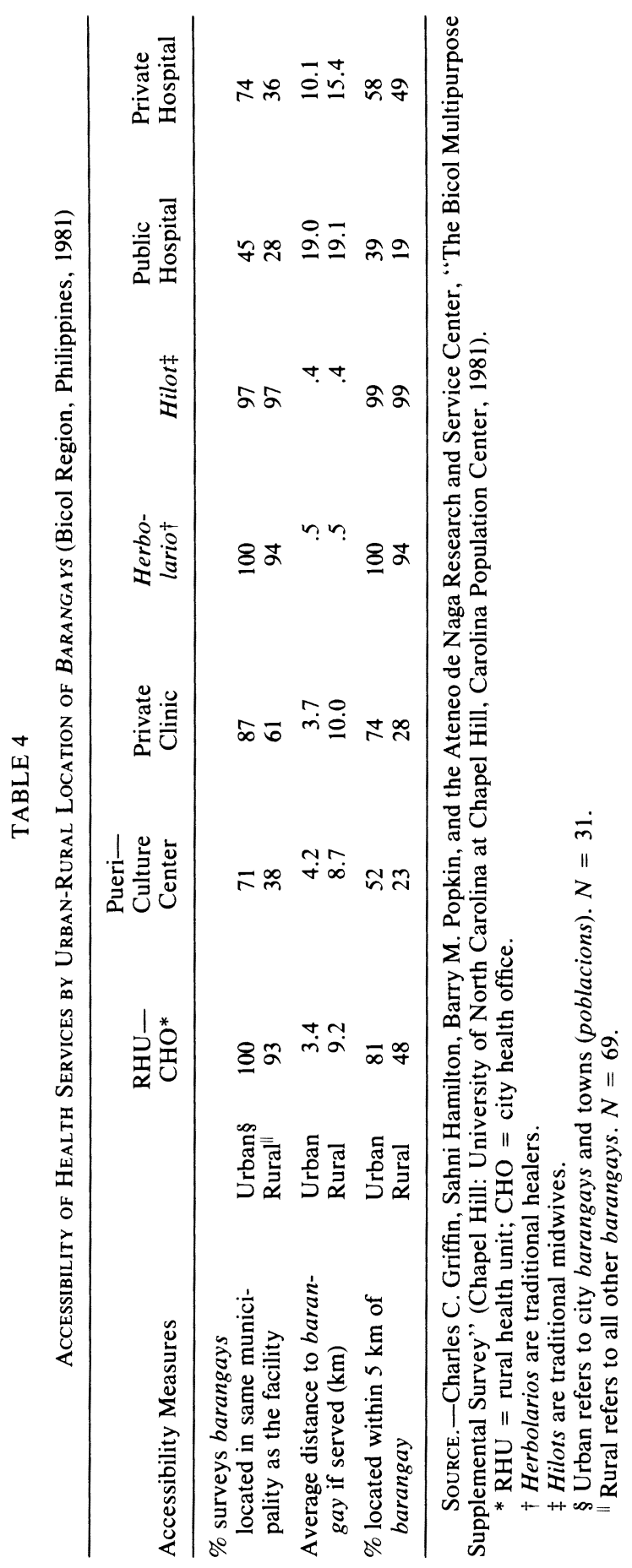


high. For example, private doctors are at least 20 times more expensive than public clinics, yet prices do not seem to deter private doctor visits.

A second cost factor is distance. The idea that distance is a major impediment to using modern medical services in the Third World is so intuitively obvious that it is simply taken as a given. We find, however, that this relationship is not so clear for our Filipino sample. Only in our delivery model does travel time to a modern clinic affect practitioner choice, and, in that case, it does so by slightly reducing the probability of choosing a modern, relative to a traditional, birth.

A possible explanation for the counterintuitive lack of importance for distance is the existence of a threshold beyond which distance becomes important. We apparently do not reach this threshold for our Bicol sample even though the maximum distance values for the outpatient samples are 54 kilometers to a public facility, 37 kilometers to a private facility, and 19 kilometers to a traditional healer. Maximum travel times are 4 hours to a public facility, 3.9 hours to a private facility, and 1.25 hours to a traditional healer. A trip to a modern clinic is an all-day affair for some people in our sample. Because no communication system is available in outlying barangays to arrange an appointment, longer trips also contain a fair amount of risk that at the end of 4 hours the hoped-for care will not be available.

Our discussion of distance has two major implications. First, if there is a threshold beyond which distance and travel time dictate medical care choices for our Bicol sample, it appears to be outside the very large range of distances observed. The demand analysis suggests that for this specific poor region in the Philippines, distance is not nearly as important to health service demand as it has often been assumed to be. Second, if our finding that transportation time and cost do not deter users can be generalized, the use of more centralized clinics that offer a higher level of care may be a feasible alternative to fielding huge numbers of paraprofessionals. Finding that for our sample distance or travel costs are less important than commonly thought is not to suggest that policies aimed at lowering travel costs should be abandoned, only that the marginal benefit of reducing travel time to zero for virtually everyone may not be worth the effort. More research for other samples is certainly called for.

A third cost factor is waiting time. We find that this variable also does not seem to deter visits. The lack of a significant effect of waiting time on demand may partially be explained by quality considerations. People may simply expect to wait for a doctor or healer who has a good reputation. Efforts to reduce waiting time will undoubtedly reduce patients' costs. However, unless the quality and cost effects can be isolated from each other, this exercise may have less impact on patients' behavior than intended. Reducing waiting time at a public clinic 
may not affect use patterns if people going to private, modern or traditional facilities choose to do so partially because of long waiting times caused by perceived high quality at those facilities. A related point is that raising the quality of services may in actuality be a substitute for reducing waiting time.

A finding consistent with those for other cost variables is the result that drug costs do not significantly affect practitioner choice for the Bicol sample, even though our drug cost index at private and public clinics is in many cases extremely high. This is simply another piece of evidence that the cash costs of using medical care have little effect on practitioner choices for our sample.

To conclude, we have examined almost all important direct costs of using medical services: visit prices, drug costs, transport costs, transport time, and waiting time. Despite the attractiveness of the widely held assumption that these are important impediments to using medical services, we do not find this to be the case for our Filipino sample. The economic costs of using medical care do not seem to greatly affect demand patterns, either for services that are probably considered by patients to be essential-outpatient and delivery careor for services that are more optional in nature-prenatal, well-baby, and immunization care.

A related issue is the presumed importance of income as a determinant of medical service use. In our demand estimations, income is usually statistically significant, but in quantitative terms, it is not an important factor that determines whether or where medical services are purchased. We find that the poorest Bicolanos either stay home or pay substantial fees to use private clinics for outpatient care; that the poorest pregnant women are the least likely to use prenatal, well-baby,

TABLE 5

Outpatient and Delivery Expenditure Patterns by Asset Quartile (Bicol Region, Philippines, 1978)

\begin{tabular}{llccc}
\hline & \multicolumn{2}{l}{ Adult } & & \\
\cline { 2 - 4 } $\begin{array}{l}\text { Asset } \\
\text { Quartile }\end{array}$ & $\begin{array}{c}\text { If Visit } \\
\text { Made }\end{array}$ & $\begin{array}{c}\text { If No } \\
\text { Visit }\end{array}$ & $\begin{array}{c}\text { Drug } \\
\text { Purchases } \dagger\end{array}$ & $\begin{array}{c}\text { Average Delivery } \\
\text { ExPENSES (P) }\end{array}$ \\
\hline 1 (poorest) & 27.03 & 1.76 & 22.58 & 40.59 \\
2 & 16.96 & 2.10 & 21.25 & 33.65 \\
3 & 11.62 & 3.76 & 19.54 & 53.95 \\
4 (richest) & 27.57 & 1.49 & 44.79 & 183.74 \\
\hline
\end{tabular}

Source.-Barry M. Popkin and Sulpico S. Roco, Jr., with Perfecto Bragais, Jr., and C. Stuart Callison, 1978 Bicol Multipurpose Survey, vol. 1, Survey Design and Implementation (Manila: USAID, 1979).

* Adults: ages 14 and above.

$\dagger$ The drug expenditure cols. refer only to those who bought drugs, about $70 \%$ of each quartile. 
or immunization services; and that the poorest quartile tends to pay a premium to use traditional midwives for deliveries. This behavior is reflected in the expenditure data in table 5, which show that the poorest quartile spends as much or more on outpatient and obstetrical care as the other quartiles.

Thus we have the odd result that the Philippine government's effort to follow a well-accepted strategy-building free clinics as a way to reach the poor-may, for our sample, have resulted in the services not reaching the poorest of the intended recipients because of their unexpected consumption behavior. The converse is also true: free government clinics appear to serve many higher-income patients who could probably afford to pay something, especially for mother-andchild health services.

The important point is that even though these consumption patterns are correlated with income quartiles, poverty per se is not the cause of the poorest quartile's medical consumption decisions. Our demand models show that other correlates of income, particularly education and urban residence, tend to account for the behavior patterns of the poorest group. Because it is not indigents' poverty that keeps them from using modern health services, a service supply system designed to overcome the low-income barrier may be focused on an assumed constraining factor that is not overwhelmingly important, while missing others that are-knowledge and orientation (or habit). 


\section{Appendix}

TABLE A1

INDEPENDENT VARIABLE DEFINITIONS

\begin{tabular}{|c|c|}
\hline $\begin{array}{l}\text { Independent Variables } \\
\text { (Unit of Measure) }\end{array}$ & Variable Definitions \\
\hline $\begin{array}{l}\text { Visit price }(\mathrm{P}) \\
\text { Waiting time (min) } \\
\text { Attendant: } \\
\text { Traditional } \\
\text { Public } \\
\text { Private } \\
\text { Drug cost }(\mathrm{P}) \\
\text { Traditional practitioner } \\
\text { does not treat five } \\
\text { common illnesses }\end{array}$ & $\begin{array}{l}\text { These are facility-reported variables for the cost, waiting } \\
\text { time, usual attendant, and index of drug costs for each } \\
\text { service (outpatient, prenatal, etc.). We select prices } \\
\text { from the closest facility of each type for all } 100 \text { sample } \\
\text { barangays to use as the prices that face people in each } \\
\text { barangay. The usual attendant is used as a quality } \\
\text { variable. For traditional healers, the quality variable is } \\
\text { a dummy variable for whether they treat any of the five } \\
\text { common illnesses asked about in the survey. }\end{array}$ \\
\hline $\begin{array}{l}\text { Transport time }(\mathrm{min}) \\
\text { Transport cost }(\mathrm{P}): \\
\text { Traditional } \\
\text { Public } \\
\text { Private }\end{array}$ & $\begin{array}{l}\text { Transport time and transport cost are given for a one-way } \\
\text { trip from the center of the barangay of residence to } \\
\text { each type of facility, using the most common means of } \\
\text { transport. Walking trips have zero cost but positive } \\
\text { transport time. }\end{array}$ \\
\hline Insured? & $\begin{array}{l}\text { We know whether each household has health insurance } \\
\text { and who is covered. This variable equals } 1 \text { if the } \\
\text { individual is covered by health insurance. }\end{array}$ \\
\hline Asset value & $\begin{array}{l}\text { We do not have a reliable income estimate for the Bicol } \\
\text { sample because of coding errors embedded in the raw } \\
\text { data. As a proxy, we use the value of personal } \\
\text { assets-house, lot, furniture, appliances, and vehicles. } \\
\text { This variable probably is a better measure of } \\
\text { permanent income than of current income. }\end{array}$ \\
\hline $\begin{array}{l}\text { Age } \\
\text { Mother's age }\end{array}$ & $\begin{array}{l}\text { Age of the individual. For child outpatients, we use } \\
\text { mothers' ages on the assumption that the mother } \\
\text { makes medical service consumption decisions for her } \\
\text { children. }\end{array}$ \\
\hline $\begin{array}{l}\text { Sex } \\
\text { Baby's sex }\end{array}$ & $\begin{array}{l}\text { These qualitative variables equal } 1 \text { if the individual is } \\
\text { male. }\end{array}$ \\
\hline $\begin{array}{l}\text { Education } \\
\text { Mother's education }\end{array}$ & $\begin{array}{l}\text { Highest completed grade. Mother's education is used } \\
\text { where appropriate for children (see "age" above). }\end{array}$ \\
\hline Serious illness & $\begin{array}{l}\text { The household respondent, usually the mother, was } \\
\text { asked whether anyone in the household was sick in the } \\
\text { previous month and whether that illness was very } \\
\text { serious, serious, or not serious. If she replied very } \\
\text { serious, this qualitative variable equals } 1 \text {. }\end{array}$ \\
\hline Mother home & $\begin{array}{l}\text { If the mother either does not work or works at home, this } \\
\text { variable equals } 1 \text {. }\end{array}$ \\
\hline No. of living children & Self-explanatory. \\
\hline Had modern delivery? & $\begin{array}{l}\text { If the baby who is considered eligible for well-baby care } \\
\text { or immunizations was delivered by a trained midwife } \\
\text { or a physician, at home or in a clinic, this variable } \\
\text { equals } 1 \text {. }\end{array}$ \\
\hline
\end{tabular}


TABLE A2

Sample Statistics for Outpatients (Bicol Region, Philippines, 1978)

\begin{tabular}{|c|c|c|c|c|}
\hline \multirow[b]{2}{*}{ INDEPENDENT VARIABLES } & \multicolumn{2}{|c|}{ Adults } & \multicolumn{2}{|c|}{ Children } \\
\hline & Mean & SD & Mean & SD \\
\hline \multicolumn{5}{|l|}{ Cash price $(\mathrm{P})$ : } \\
\hline Traditional & 2.1 & 2.0 & 1.8 & 1.5 \\
\hline Public & .3 & .9 & .4 & 1.2 \\
\hline Private & 11.0 & 8.9 & 12.5 & 7.2 \\
\hline \multicolumn{5}{|l|}{ Transport cost $(\mathrm{P})$ : } \\
\hline To traditional & .1 & .4 & .1 & .5 \\
\hline To public & 1.7 & 4.6 & 1.1 & 2.0 \\
\hline To private & 1.1 & 1.4 & 1.2 & 1.3 \\
\hline \multicolumn{5}{|l|}{ Transport time (min): } \\
\hline To traditional & 5.4 & 10.9 & 7.5 & 23.6 \\
\hline To public & 24.0 & 33.8 & 25.0 & 39.0 \\
\hline To private & 24.6 & 31.7 & 26.3 & 38.8 \\
\hline \multicolumn{5}{|l|}{ Waiting time (min): } \\
\hline Traditional & 3.4 & 15.1 & 4.2 & 18.0 \\
\hline Public & 4.2 & 6.9 & 3.5 & 6.1 \\
\hline Private & 4.5 & 8.4 & 3.3 & 7.3 \\
\hline \multicolumn{5}{|l|}{ Usually examined by a doctor: } \\
\hline Public $(0=$ no, $1=$ yes $)$ & .6 & .5 & .5 & .5 \\
\hline Private $(0=$ no, $1=$ yes $)$ & .8 & .4 & 1.0 & .1 \\
\hline \multicolumn{5}{|l|}{$\begin{array}{l}\text { Traditional practitioner does } \\
\text { not treat five common illnesses }\end{array}$} \\
\hline $0=$ does treat, $1=$ does not) & .2 & .4 & .1 & .3 \\
\hline \multicolumn{5}{|l|}{ Drug cost index $(\mathrm{P})$ : } \\
\hline Traditional & .2 & .7 & .4 & 1.4 \\
\hline Public & 18.1 & 43.8 & 22.7 & 49.2 \\
\hline Private & 179.6 & 227.9 & 273.6 & 282.7 \\
\hline \multicolumn{5}{|l|}{ Sick person insured } \\
\hline$(1=$ insured $)$ & .1 & .3 & .1 & .3 \\
\hline \multicolumn{5}{|l|}{ Current value of household } \\
\hline assets $(\mathrm{P})$ & 5,197 & 12,540 & 4,240 & 12,111 \\
\hline Age of sick person (years) & 40.3 & 17.5 & 5.0 & 3.7 \\
\hline \multicolumn{5}{|l|}{ Sex of sick person } \\
\hline$(0=$ female, $1=$ male $)$ & .5 & .5 & .5 & .5 \\
\hline \multicolumn{5}{|l|}{ Location of residence } \\
\hline$(0=$ rural, $1=$ urban $)$ & .2 & .4 & .3 & .4 \\
\hline \multicolumn{5}{|l|}{$\begin{array}{l}\text { Education of sick adult } \\
\text { (or mother, for children) }\end{array}$} \\
\hline (completed grades) & 6.6 & 3.6 & 7.3 & 3.3 \\
\hline \multicolumn{5}{|l|}{ Seriousness of illness } \\
\hline$(0=$ not serious, $1=$ serious $)$ & .3 & .4 & .2 & .4 \\
\hline Mother either works at home or & & & & \\
\hline does not work $(1=$ home $)$ & ... & . & .8 & .4 \\
\hline
\end{tabular}




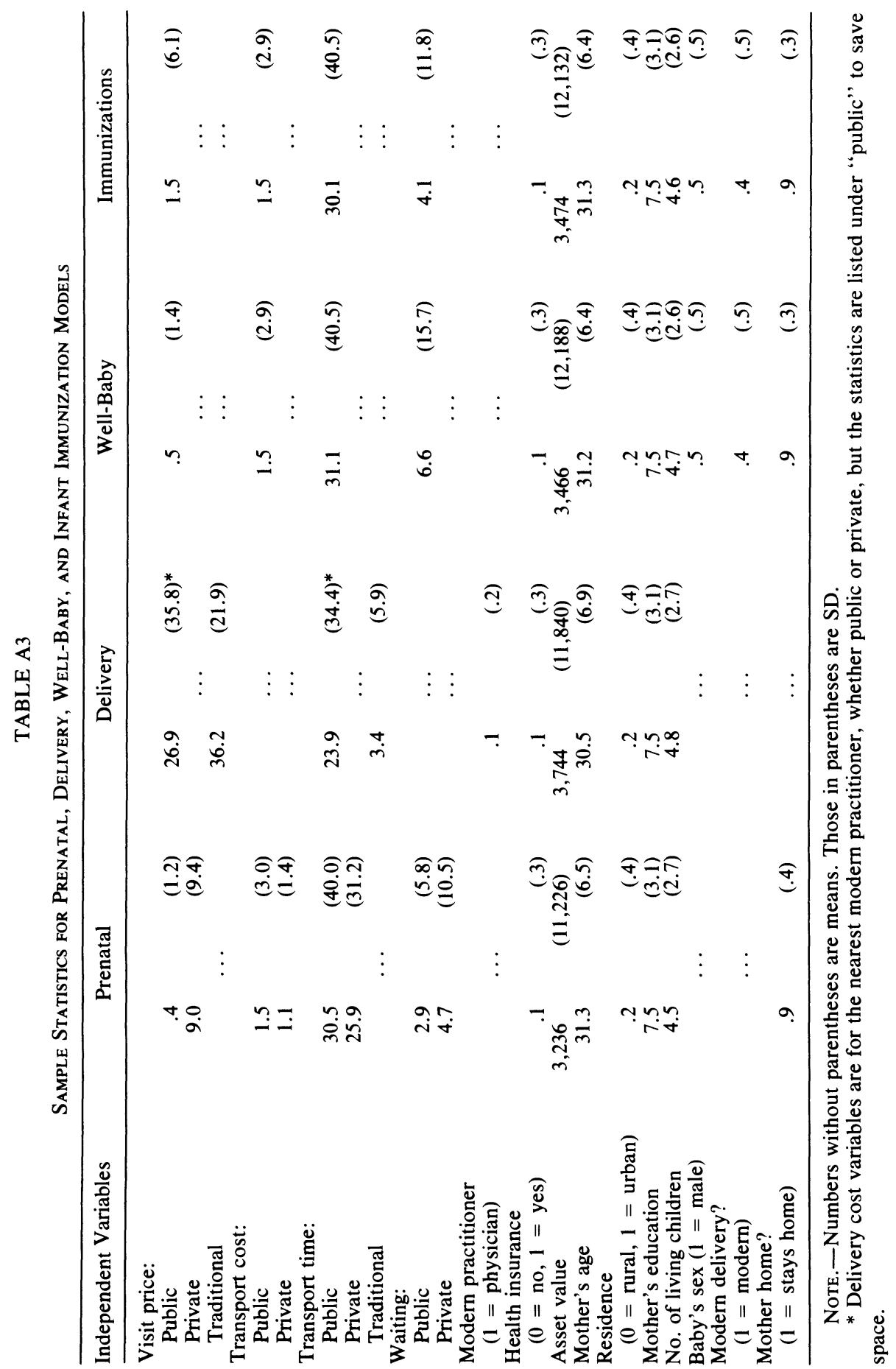




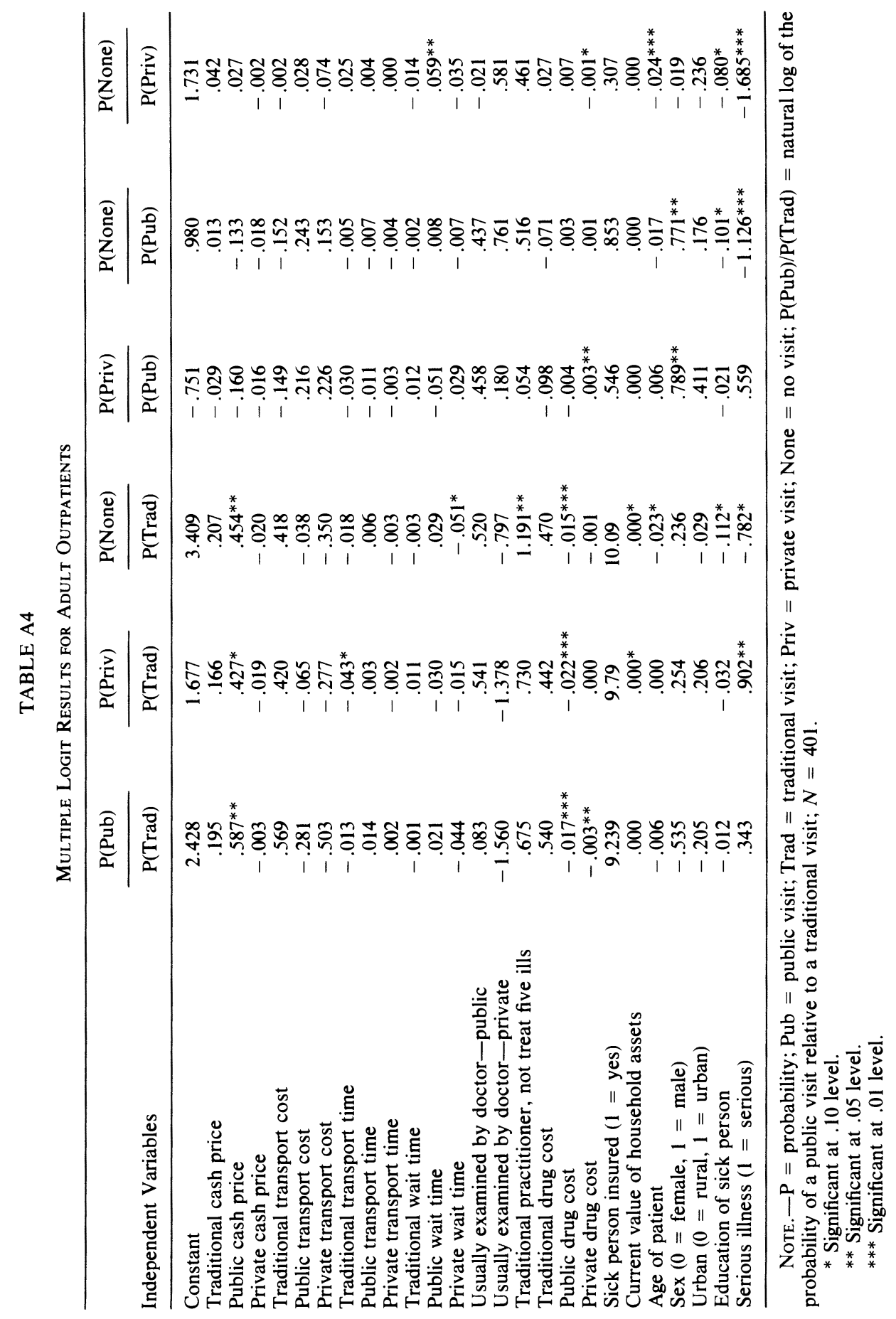




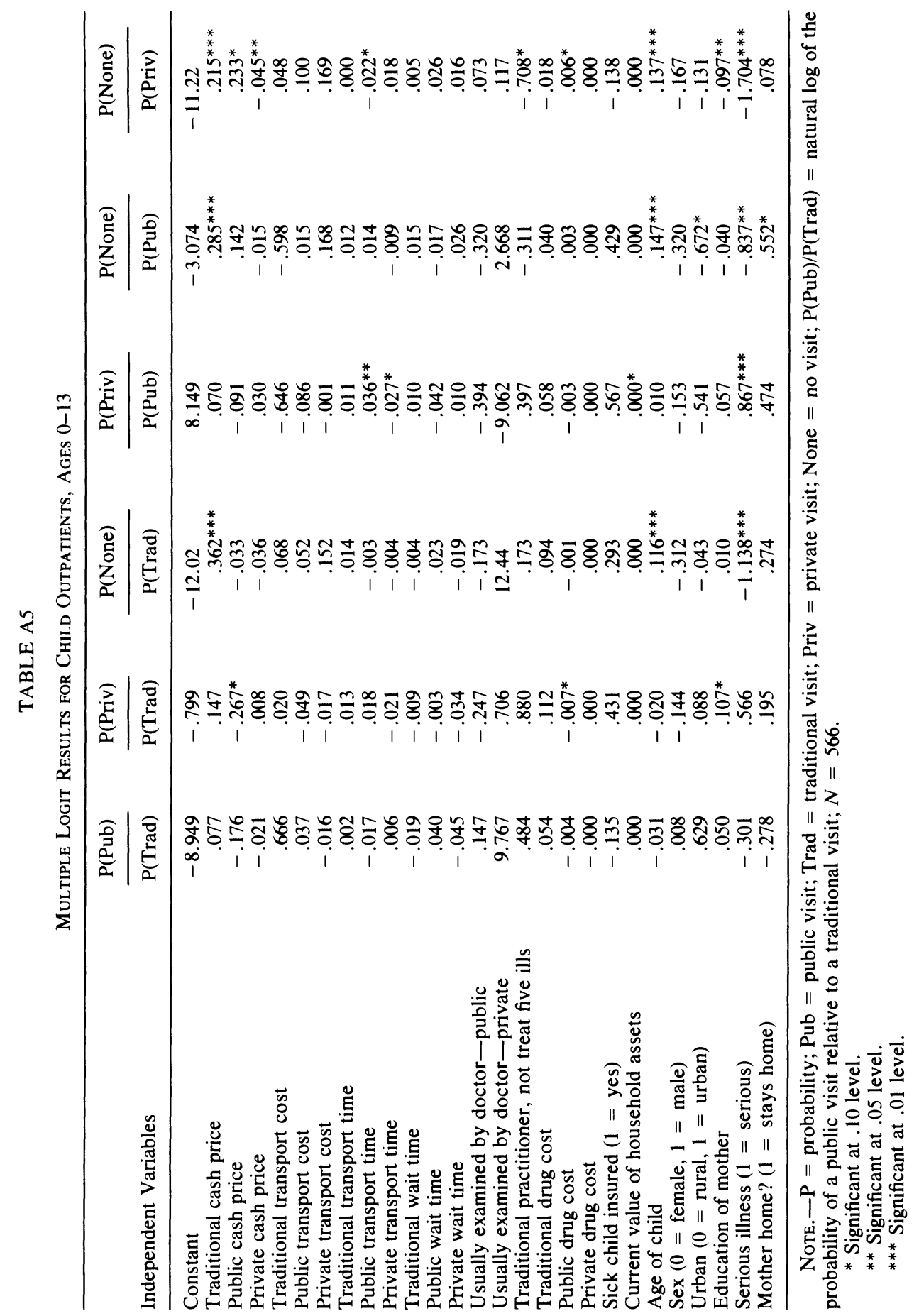


TABLE A6

Tobit Results for Number of Prenatal Visits

\begin{tabular}{|c|c|c|}
\hline Independent Variables & Coefficient & $\begin{array}{c}\text { Asymptotic } \\
T \text {-statistic }\end{array}$ \\
\hline Constant & -4.517 & -2.459 \\
\hline Price of prenatal visit-public & $-.440^{*}$ & -2.046 \\
\hline Price of prenatal visit-private & -.031 & -1.130 \\
\hline Transport cost to public facility & .111 & 1.150 \\
\hline Transport cost to private facility & .239 & .707 \\
\hline Transport time to public facility & $-.019^{*}$ & -2.022 \\
\hline Transport time to private facility & -.023 & -1.413 \\
\hline Usual wait for prenatal visit_-public facility & .017 & .374 \\
\hline Usual wait for prenatal visit-private facility & -.010 & -.382 \\
\hline \multicolumn{3}{|l|}{ Mother covered by health insurance } \\
\hline$(0=$ no, $1=$ yes $)$ & -.202 & -.216 \\
\hline Current value of household assets & $.000^{*}$ & 2.570 \\
\hline Mother's age & $.155^{* *}$ & 2.594 \\
\hline Location of residence $(0=$ rural, $1=$ urban $)$ & $1.371^{*}$ & 2.117 \\
\hline Mother's education & $.328 * *$ & 3.637 \\
\hline No. of living children & $-.360^{*}$ & -2.413 \\
\hline \multicolumn{3}{|l|}{ Mother works at home or does not work } \\
\hline$(0=$ works away, $1=$ stays home $)$ & -.420 & -.594 \\
\hline
\end{tabular}

$$
\text { Note. }-N=495 . \quad * \text { Significant at } .05 \text { level. } \quad * * \text { Significant at } .01 \text { level. }
$$

TABLE A7

Multiple Logit Results for Choice of Modern Clinic Delivery, Modern Home Delivery, or Traditional Home Delivery

\begin{tabular}{|c|c|c|c|}
\hline & $\mathrm{P}($ Modern Clinic) & P(Trad Home) & P(Trad Home $)$ \\
\hline Independent Variables & P(Modern Home) & P(Modern Home $)$ & P(Mod Clinic) \\
\hline Constant & -4.595 & 1.250 & 5.845 \\
\hline $\begin{array}{l}\text { Price of home delivery- } \\
\text { traditional midwife }\end{array}$ & .010 & .007 & -.003 \\
\hline $\begin{array}{l}\text { Price of home delivery- } \\
\text { closest modern practitioner }\end{array}$ & $.014^{* * *}$ & .000 & $-.014 * * *$ \\
\hline $\begin{array}{l}\text { Transport time for } \\
\text { traditional midwife }\end{array}$ & .000 & -.009 & -.009 \\
\hline $\begin{array}{l}\text { Transport time to closest } \\
\text { modern facility }\end{array}$ & .002 & $.010^{* *}$ & .008 \\
\hline $\begin{array}{l}\text { Modern home practitioner } \\
\text { is a physician }\end{array}$ & $-2.215^{*}$ & -.229 & $1.985^{*}$ \\
\hline $\begin{array}{l}\text { Mother insured }(0=\text { not } \\
\text { insured, } 1=\text { insured })\end{array}$ & -.364 & -.233 & .131 \\
\hline $\begin{array}{l}\text { Current value of household } \\
\text { assets }\end{array}$ & .000 & -.000 & -.000 \\
\hline $\begin{array}{l}\text { Age of mother } \\
\text { Location of residence }\end{array}$ & .025 & -.005 & -.030 \\
\hline$(0=$ rural, $1=$ urban $)$ & .335 & $-.685^{* * *}$ & $-1.020^{* *}$ \\
\hline Mother's education & $.189 * * *$ & $-.077^{*}$ & $-.266^{* * *}$ \\
\hline No. of living children & -.029 & .027 & .056 \\
\hline
\end{tabular}

NoTE.-P = probability; Trad = traditional midwife; Mod = modern trained attendant; $\mathrm{P}($ Modern Clinic) $/ \mathrm{P}($ Modern Home $)=$ natural log of the probability of a modern clinic delivery relative to a modern home delivery; $N=482$.

* Significant at .10 level. ** Significant at .05 level. *** Significant at .01 level. 
TABLE A8

Probit Results for Decision to Seek Well-Baby Care

\begin{tabular}{|c|c|c|}
\hline Independent Variables & Coefficient & $\begin{array}{l}\text { Asymptotic } \\
T \text {-statistic }\end{array}$ \\
\hline Constant & -1.546 & -3.023 \\
\hline $\begin{array}{l}\text { Price of well-baby visit-closest public } \\
\text { facility offering well-baby care }\end{array}$ & -.053 & -1.088 \\
\hline Transport cost to public facility & -.050 & -1.101 \\
\hline Transport time to public facility & .000 & -.079 \\
\hline $\begin{array}{l}\text { Usual wait for well-baby visit-public } \\
\text { facility }\end{array}$ & $.014^{* * *}$ & 3.162 \\
\hline $\begin{array}{l}\text { Mother covered by health insurance } \\
(0=\text { no, } 1=\text { yes })\end{array}$ & .246 & .865 \\
\hline Current value of household assets & $-.000^{* * *}$ & -2.634 \\
\hline Mother's age & -.002 & -.091 \\
\hline $\begin{array}{l}\text { Location of residence }(0=\text { rural, } \\
1=\text { urban })\end{array}$ & $.319^{*}$ & 1.866 \\
\hline Mother's education & $.091^{* * *}$ & 3.414 \\
\hline No. of living children & .023 & .555 \\
\hline Sex of baby $(0=$ female, $1=$ male $)$ & .157 & 1.175 \\
\hline $\begin{array}{l}\text { Type of delivery }(0=\text { traditional, } \\
1=\text { modern })\end{array}$ & $.395^{* * *}$ & 2.729 \\
\hline $\begin{array}{l}\text { Mother works at home or does not work } \\
(0=\text { works away, } 1=\text { stays home })\end{array}$ & $.409^{* *}$ & 1.988 \\
\hline
\end{tabular}

Note. -2.0 times the $\log$ of the likelihood ratio $=25.9906$; regression significant at .01 level; $N=407$.

* Significant at .10 level. ** Significant at .05 level. *** Significant at .01 level.

TABLE A9

Probit Results for Decision to Seek Infant Immunizations

\begin{tabular}{|c|c|c|}
\hline Independent Variables & Coefficient & $\begin{array}{l}\text { Asymptotic } \\
T \text {-statistic }\end{array}$ \\
\hline Constant & -3.548 & -4.156 \\
\hline $\begin{array}{l}\text { Price of immunization-closest public } \\
\text { facility offering immunizations }\end{array}$ & $.029^{*}$ & 1.699 \\
\hline Transport cost to public facility & .034 & .622 \\
\hline Transport time to public facility & -.011 & -1.472 \\
\hline $\begin{array}{l}\text { Usual wait for immunization visit-public } \\
\text { facility }\end{array}$ & .004 & .416 \\
\hline $\begin{array}{l}\text { Mother covered by health insurance } \\
(0=\text { no, } 1=\text { yes })\end{array}$ & $.771^{* *}$ & 2.359 \\
\hline Current value of household assets & -.000 & -1.349 \\
\hline Mother's age & $.074^{* * *}$ & 2.811 \\
\hline $\begin{array}{l}\text { Location of residence }(0=\text { rural, } \\
1=\text { urban) }\end{array}$ & -.267 & -.951 \\
\hline Mother's education & $.063 *$ & 1.697 \\
\hline No. of living children & $-.153^{* *}$ & -2.229 \\
\hline Sex of baby $(0=$ female, $1=$ male $)$ & -.039 & -.178 \\
\hline $\begin{array}{l}\text { Type of delivery }(0=\text { traditional, } \\
1=\text { modern })\end{array}$ & .031 & .131 \\
\hline $\begin{array}{l}\text { Mother works at home or does not work } \\
(0=\text { works away, } 1=\text { stays home })\end{array}$ & .041 & .125 \\
\hline
\end{tabular}

NotE. --2.0 times the $\log$ of the likelihood ratio $=56.004$; regression significant at .025 level, $N=406$.

* Significant at .10 level. ** Significant at .05 level. *** Significant at .01 level. 
Notes

* The project report from which this article is excerpted was funded by the Program and Policy Coordination Division of USAID, under the sponsorship of Maureen Lewis. The 1978 household data used in the analysis come from the Bicol Multipurpose Survey, funded by the Bicol River Basin Development Program (BRBDP) and USAID. The 1981 facility data were collected under the sponsorship of the Carolina Population Center. We are indebted to Maureen Lewis for her assistance and for careful readings and extensive comments on the written materials. We also thank the BRBDP and USAID, in particular Don Wadley and David Hessen, for providing access to the 1978 data, and Dr. Florentino S. Solon and the Research and Service Center, Ateneo de Naga, Philippines, for help in collecting the 1981 data.

1. See Hyman Joseph, "Empirical Research on the Demand for Health Care," Inquiry 8 (1971): 61-71; Jan Paul Acton, "Demand for Health Care When Time Prices Vary More than Money Prices," Paper no. R-1189-OEO/ NYC (Santa Monica, Calif.: Rand Corp., 1973); Michael Grossman, The Demand for Health: A Theoretical and Empirical Investigation, National Bureau of Economic Research, Occasional Paper no. 119 (New York: Rand Corp., 1972); Charles E. Phelps and Joseph P. Newhouse, "Coinsurance and the Demand for Medical Services," Paper no. R-964-OEO/NC (Santa Monica, Calif.: Rand Corp., 1973); Arleen Leibowitz and Bernard Friedman, "Family Bequests and the Derived Demand for Health Inputs," Economic Inquiry 17 (July 1979): 419-34; Laurence A. Miners, "The Family's Demand for Health: A Rural Investigation" (Ph.D. diss., University of North Carolina at Chapel Hill, 1979); and Fred Goldman and Michael Grossman, "The Demand for Pediatric Care: An Hedonic Approach," Journal of Political Economy 86 (April 1978): 259-80.

2. Peter S. Heller, "A Model of the Demand for Medical and Health Services in Peninsular Malaysia," Social Science and Medicine 16 (1982): 267-84.

3. John S. Akin, Charles C. Griffin, David K. Guilkey, and Barry M. Popkin, The Demand for Primary Health Services in the Third World (Totowa, N.J.: Littlefield, Adams \& Co., 1984).

4. Cecilio L. Adorna, "The Distribution of Health Resources in the Philippines" (Master's thesis, University of the Philippines, 1976).

5. The World Bank, World Development Report 1983 (New York: Oxford University Press, 1983).

6. Barry M. Popkin and Sulpico S. Roco, Jr., with Perfecto Bragais, Jr., and C. Stuart Callison, 1978 Bicol Multipurpose Survey, vol. 1, Survey Design and Implementation (Manila: USAID, 1979).

7. John S. Akin, David K. Guilkey, and Barry M. Popkin, "The Demand for Child Health Services in the Philippines," Social Science and Medicine 15C (December 1981): 249-57.

8. George G. Judge, William E. Griffiths, R. Carter Hill, and TsoungChao Lee, The Theory and Practice of Econometrics (New York: John Wiley \& Sons, 1980), pp. 593-608; T. Amemiya, "Qualitative Response Models: A Survey," Journal of Economic Literature 19 (1981): 1483-1536.

9. Akin et al., The Demand for Primary Health Services in the Third World.

10. Forrest D. Colburn, Guatemala's Rural Health Paraprofessionals, Special Series on Paraprofessionals no. 2 (Ithaca, N.Y.: Cornell University, Center for International Studies, Rural Development Committee, 1981); Robert E. Hall, The Village Health Worker Approach to Rural Health Care: The Case of Senegal, Special Series on Paraprofessionals no. 5 (Ithaca: Cornell University, Center for International Studies, Rural Development Committee, 1981); Margaret Burns Parlato and Michael N. Favin, Primary Health Care: Progress and Problems: An Analysis of 52 AID-assisted Projects (Washington, D.C.: American Public Health Association, 1982). 